Revista Brasileira de Meteorologia, v.23, n.1, 73-87, 2008

\title{
SENSIBILIDADE INTRASAZONAL DE UM DOWNSCALING DINÂMICO DE PRECIPITAÇÃO (1971-2000): UMA ANÁLISE NA BACIA HIDROGRÁFICA DO AÇUDE CASTANHÃO-CE
}

\author{
JOSÉ MARIA BRABO ALVES, JOSÉ NILSON BESERRA CAMPOS e LUIS SÉRGIO VASCONCELOS \\ NASCIMENTO
}

\author{
Fundação Cearense de Meteorologia e Recursos Hídricos (FUNCEME) \\ Av. Rui Barbosa, 1246, Aldeota - Fortaleza-CE - 60.115.221 \\ email: brabo@funceme.br
}

Recebido Novembro 2006 - Aceito Fevereiro 2007

\begin{abstract}
RESUMO
Em regiões semi-áridas como parte do Nordeste do Brasil (NEB) reservatórios hidrícos artificiais são essências para acumular água no período chuvoso e suprir sua demanda por liberação no período seco. Por este fato, é importante o conhecimento da variabilidade pluviométrica na bacia hidrográfica desses reservatórios. Os resultados aqui apresentados mostram comparações entre dados observados e simulação via modelagem dinâmica para a bacia do Açude Castanhão-Ce com ênfase a escala intrasazonal. A variabilidade interanual da precipitação intrasazonal (1971-2000) simulada pelo modelo regional espectral (MRE) tem um erro sistemático que subestima os totais observados (pentadais e quinzenais), principalmente no período de fevereiro a maio, e superestima esses totais em janeiro e junho. Entretanto, foram verificadas também maiores (menores) diferenças quantitativas nesses totais na subestimativa nas décadas de 1970-1980-1990 e 1990-2000. Para anos de constraste climáticos (La Niña, El Niño e Normais), o MRE nas escalas pentadal, quinzenal e mensal capturou com bom desempenho o sinal da anomalia relacionado à precipitação observada predominando anomalia positiva para os anos de La Niña e em torno da média a negativa para os anos Normais e de El Niño, em particular durante fevereiro a maio. Essa característica foi também verificada nos dados de precipitação observada na bacia.
\end{abstract}

Palavras -chave : intrasazonal, redução de escala, incremento de previsão de precipitação, modelagem regional.

\begin{abstract}
SENSIBILITY OF INTRASEASONAL PRECIPITATION DINAMICAL DOWNSCALING: AN ANALYSIS IN WATERSHED OF CASTANHÃO-CE DAMS

In arid regions as northeast part of Brazil (NEB) artificial water reservoirs are essences to accumulate water in the rainy period and to supply its demand for release in the dry period. For this fact, the knowledge of the pluviometric variability in the hydrographic basin of these reservoirs is important. The results presented here show comparisons between observed data and simulation from dynamic modeling for the basin of the Castanhão-Ce Dam with emphases the intra seasonal scale. The interanual variability of intra-seasonal precipitation (1971-2000) simulated by the spectral regional model (MRE) has a systematic bias that underestimation the observed totals (pentads and biweekly), mainly in the period of February the May, and overestimates these totals in January and June. However, were also verified bigger (lesser) quantitative differences in these totals in the sub estimation in the decades of 1970-1980-1990 e (1990-2000). For climatic years of contrast (La Niña, El Niño and Normal), the MRE in the scales pentad, biweekly and monthly captured with good performance the signal of the anomaly in relation to the precipitation observed, predominating positive anomaly for the years of La Niña, and around the average the refusal for the Normal years and of El Niño, in particular during February the May. This characteristic also was verified in the precipitation data observed in the basin.
\end{abstract}

Key-Words: intraseasonal, downscaling, improved forecast precipitation, regional modeling 


\section{INTRODUÇÃO}

A relação oferta versus demanda de água tem exigido cada vez mais o aprimoramento de previsões de precipitação pluviométrica, para o seu uso em modelos hidrológicos chuvavazão em escalas intrasazonal (abaixo de um trimestre ou mês) com objetivo de otimizar o uso da água. Em regiões semi-áridas como é caso do estudo em questão, a disponibilidade da previsão de precipitação na escala da bacia hidrográfica é crucial para o operador do sistema (reservatório) tomar suas decisões.

Nos últimos anos, em várias áreas do Brasil, previsões meteorológicas de tempo (escala de dias) e sazonal (acima da escala mensal) têm sido utilizadas como dados de entrada na modelagem de sistemas de operação de reservatórios (Galvão, 1999; Collischonn, 2001; Tucci et al. 2003; Galvão et al; 2005 e outros). Hoje, além dos modelos dinâmicos de circulação geral da atmosfera - MCGAs (com resolução em geral acima de $200 \mathrm{~km}$ ), têm-se a possibilidade de rodadas de modelos regionais - MRs (escala de dezenas de $\mathrm{km}$ ), que podem ser aninhados com dados de MCGAS que incorporam características regionais como topografia, vegetação, solo, diferenças continente-oceano, etc, não contidas nos modelos globais. Os resultados com o uso desta técnica (downscaling) apontam para um melhor desempenho na simulação e previsão de distribuição de precipitação localizada (Nobre et al., 2001; Seth et al; 2005; Sun et al. 2005; 2006). Segundo Tucci et al. (2005), "os modelos atmosféricos dinâmicos são modelos físicos tridimensionais que representam o movimento da mistura ar e vapor d'água na atmosfera, sua trocas envolvidas, sujeitos a determinadas condições iniciais e de contorno (McGuffie e Henderson-Sellers, 2001)".

Neste estudo foi feita uma análise preliminar dos resultados da simulação de um MR (versão de 1997 - MRE/97) aninhado em um modelo global - ECHAM4.5 para o período de 1971-2000, com ênfase nas escalas intra-sazonais na bacia hidrográfica do Açude Castanhão-Ce. Este açude foi estrategicamente construído para suprir a demanda hídrica em várias áreas do Estado do Ceará com capacidade para acumular em torno de $6.700 .000 \mathrm{~m}^{3}$ de água. Este sistema de downscaling está operacional na Fundação Cearense de Meteorologia (FUNCEME) com previsões de precipitação (desde 2001) e vazão a partir de 2006 em várias bacias hidrográficas do Estado (htpp:www.funceme.br/recursoshídricos). Embora, resultados de modelagem climática tenham baixa sensibilidade em simular/prever eventos de alta freqüência, Eventos associados às condições de tempo (variabilidade interna da atmosfera), estudos com esse objetivo são importantes para mensurar quais as contribuições da previsão climática influenciada apenas pela condição de contorno (temperatura da superfície do mar - TSM), podem ser inferidas como subsídio de médio prazo ao longo da escala intra-sazonal a usuários como agricultura, recursos hídricos, etc.

\section{DADOS E METODOLOGIA}

Apesar do Açude Castanhão ter sido construído recentemente (meados para final de 2003), a observação de precipitação pluviométrica na área de captação da sua bacia hidrográfica vem sendo feita desde início do século. Dados disponíveis de postos pluviométricos nesta bacia podem ser encontrados nos banco de dados da antiga Superintendência de Desenvolvimento do Nordeste (SUDENE), Agência Nacional de Águas (ANA) e FUNCEME. Foi escolhido o período de 19712000, coincidente com o da simulação do Modelo Regional Espectral versão de 1997 (MRE/97) com dados diários de precipitação nos meses de janeiro a junho. Foi selecionado este período, por que é nele que ocorre climatologicamente, mais de $80 \%$ de todo o aporte de água nos reservatórios hídricos do NEB. Em geral, no segundo semestre há somente retiradas para usos múltiplos e perdas por evaporação. A precipitação média diária na bacia foi calculada pelo método do polígono de Thiessen aproveitando todos os postos com informações em cada dia do período de 01 de janeiro a 30 de junho.

O Açude Castanhão e sua bacia hidrográfica localizamse na região semi-árida setor sudoeste do Estado do Ceará (Figura 1). Sua bacia tem $20.069,9 \mathrm{~km}^{2}$ com uma capacidade de armazenamento de água média mensal de 77,7 $\mathrm{mm}$. Possui $70,6 \%$ do seu território com solos cristalinos, com uma precipitação média anual de $882,6 \mathrm{~mm}$. Na parte alta da bacia, setor sul do Estado, recebe chuvas no mês de janeiro, principalmente proveniente da influência da incursão de frentes frias que se localizam no setor centro-norte do Nordeste. A partir de fevereiro as chuvas são provenientes da Zona de Convergência Intertropical (ZCIT), climatologicamente com maior intensidade nos meses de março e abril. A bacia sofre um longo período de estiagem quase sem aporte de água de julho a novembro.

O MRE usado neste estudo foi à versão hidrostática do MRE do National Center for Atmospheric Research - NCEP (Juang \& Kanamitsu, 1994) aninhado no modelo de circulação geral da atmosfera (MCGA) ECHAM4.5 - European Climate Hybrid Model versão 4.5 desenvolvido no Max Planck Institute. Esse acoplamento entre o modelo MRE e o MCGA está implementado na FUNCEME sendo usado para previsão de precipitação sobre o NEB desde 2001. Detalhes desse acoplamento podem ser encontrados nos estudos de Alves et al. (2006); Sun et al. $(2005,2006)$. O MRE foi integrado em modo de simulação com uma grade horizontal de $60 \mathrm{~km}$ por $60 \mathrm{~km}$ cobrindo a região entre $23 \mathrm{oS}-16 \mathrm{oN}$ e $53 \mathrm{oW}-3 \mathrm{oE}$ com dezoito níveis na vertical. O MCGA tem truncamento triangular no 


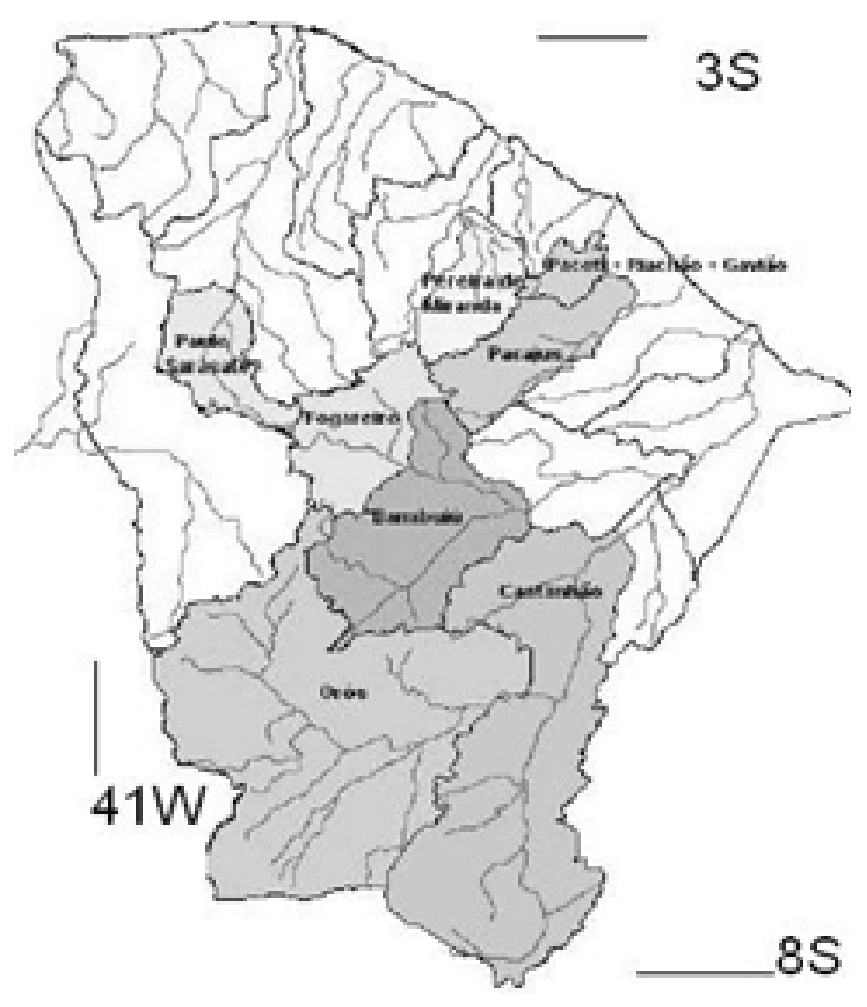

Figura 1 - Localização da bacia do Açude Castanhão no estado do Ceará e sua rede de drenagem

número de onda T42 (resolução horizontal de aproximadamente $2,8^{\circ}$ de latitude longitude) e dezenove níveis na vertical (Rockner et al, 2001). No MRE a física de superfície é calculada por um modelo de solo de duas camadas (Pan e Marth, 1997) com o uso de um tipo de solo com características entre um solo arenoso e argiloso. O tipo de vegetação usado no MRE foi de savana, em cada grade de $60 \mathrm{~km}^{2}$. O esquema de parametrização da convecção foi o relaxado de Arakawa-Shubert.

O MRE foi integrado para seis meses a partir de 01 de janeiro a 31 de junho com dez distintas condições iniciais advindas do MCGA para o período de 1971-2000. Informações do MCGA das componentes zonal e meridional do vento, umidade específica, temperatura do ar e pressão a superfície a cada 6 horas serviram de assimilação pelo MRE. Temperatura da Superfície do Mar (TSM) obtidas no banco de dados do NECP observadas nos meses de janeiro a junho de 1971-2000 foi usada como condição de contorno oceânica para o MCGA e o MRE. Maiores detalhes sobre o ECHAM4.5 e o MRE e o processo de downscaling podem ser encontrados e Sun et al. (2006).
A chuva média diária na bacia do Açude Castanhão para o MRE foi calculada por uma média aritmética dos pontos de grade inseridos na área de captação da bacia (Figura 1). Antes desse cálculo foi feita uma interpolação quadrática dos dados simulados para uma grade de aproximadamente $10 \mathrm{~km}$ x $10 \mathrm{~km}$ sobre a área da bacia hidrográfica.

A metodologia de análise compreendeu as seguintes etapas: para o período de 1971-2000 classificaram-se os anos de El Niño e La Niña no Pacífico Tropical, associados com dipolos de Temperatura da Superfície do Mar (TSM) no Atlântico Tropical. Para essa classificação foram usados dados mensais de TSM observadas nos oceanos Pacífico e Atlântico Tropicais oriundas de uma versão do Comprehensive Atmospheric-Ocean Data Set (COADS). Esse arquivo contém dados de médias mensais em pontos de grade de $1^{\circ} \mathrm{x} 1^{\circ}$ de latitude-longitude de TSM em graus celsius para um período de 1945 a 2000. Maiores detalhes desse arquivo de dados são encontrados em Da Silva et al. (1994).

Há várias definições para classificar eventos El Niño, La Niña, Neutros no Pacífico Tropical (Kiladiz, 1989; Trenberth, 1997 e outros), e de dipolos de TSM no Atlântico Tropical (Servain, 1991; Souza, 1997). O critério de classificação dos eventos foi definido como: El Niño e La Niña (anomalias maior menor em módulo do que $0,5^{\circ} \mathrm{C}$, média para novembro do ano anterior a fevereiro do ano subsequente, respectivamente) e dipolo positivo negativo de TSM quando as anomalia da TSM, média de fevereiro a maio do ano subsequente for em módulo maior menor do $0,2^{\circ} \mathrm{C}$, respectivamente. Essa diferença em módulo para definição de eventos de La Niña, El Niño devese ao fato de que a TSM tem maior variabilidade no Pacífico Tropical do que no Atlântico Tropical.

Em função desta classificação os anos tiveram a seguinte classificação: La Niña $(1971 *$ * 1972**, 1974*, 1975*, 1976**, 1984*, 1985*, 1986*, 1989*, 1996**, 1997***, 1999* e 2000*), El Niño (1973*, 1977**, 1983***, 1987**, 1988*, $1992 * * *, 1995 *$ e $1998 * * *)$, Normais $\left(1978^{* * *}, 1979 * * *\right.$, $1980 * * *, 1981 * * *, 1982 * * *, 1990 * *, 1991 *, 1993 * *$ e 1994*). Os anos grafados com um, dois e três asterisco foram anos classificados predominantemente com dipolo negativo, normal e positivo, respectivamente. A precipitação e suas anomalias na bacia do Açude Castanhão estimadas pelo MRE foram comparadas com o observado para esses anos de contrastes climáticos nas escalas de tempo diária, pentadalmente, por quinzena e mensal para o período de janeiro a junho.

Para se investigar o impacto dessa variabilidade climática tropical, nos conjuntos de anos da Tabela1, devido às forçantes e sumidouros térmicos observados nos oceanos Pacíficos e Atlântico Tropical, foi usada a técnica dos composites (Nobre, 1993, Nobre e Shukla, 1996).Essa técnica é muito utilizada para identificar padrões quando se faz agrupamentos de anos. Para 
cada composição de anos da Tabela 1 foram calculados média de longo tempo (MLT), e desvios padrões (DP) e anomalias normalizadas pelas MLTs da variável precipitação nas escalas pentadais, quinzenais e mensais. A significância estatística a 95\% para as anomalias da precipitação para as composições, citadas acima, foi calculada segundo Harrison e Larkin (1998).

Anomalias significativas foram aquelas cujo valor absoluto excedeu a $\left(z_{95}(n) \cdot \sigma\right) /(n) \frac{1}{2}$, onde n é o número de anos usado na composição, $\sigma_{\mathrm{c}}$ é o correspondente desvio padrão do composto, $z_{95}$ é o valor tabelado da distribuição $t$ Student para $n$ grau de liberdade.

Para se medir o desempenho do MRE em relação ao mais simples método de previsão usado que é a utilização da MLT foi calculada a chamada medida de redução da variância dada pela seguinte Equação 1.
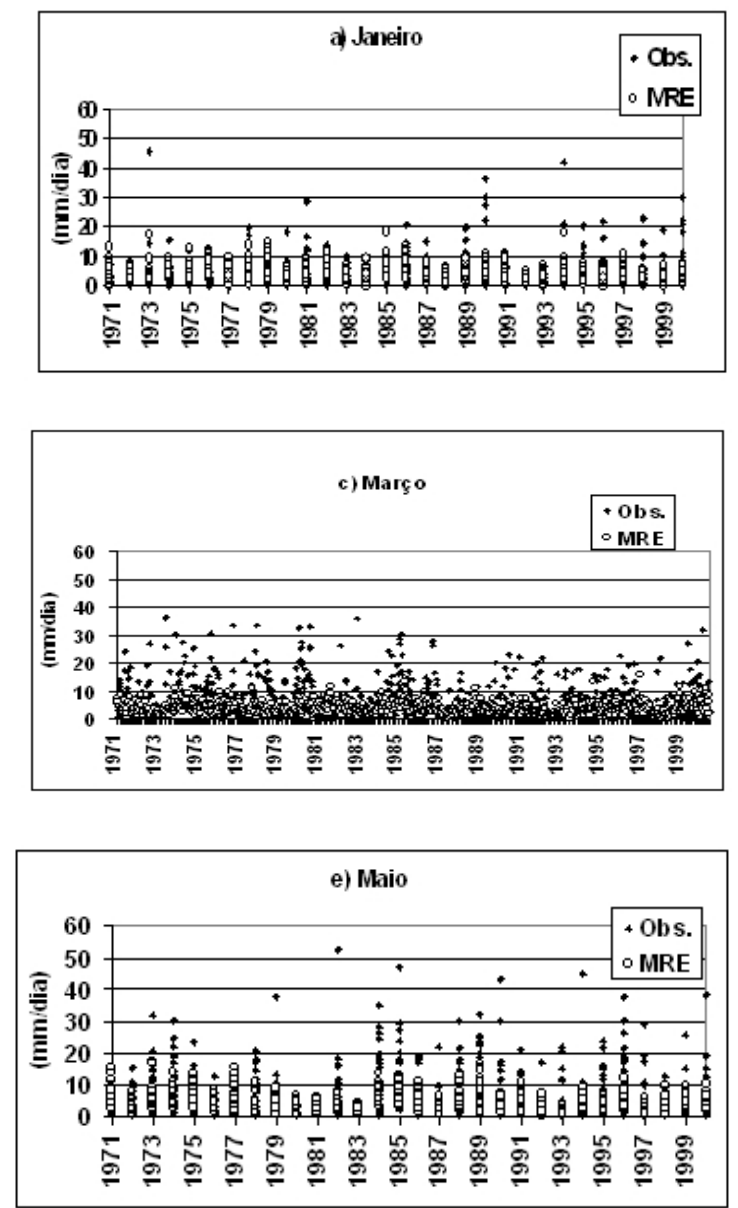

Figura 2 - Precipitação diária (mm/dia) observada e simulada na bacia hidrográfica do Açude Castanhão. a) janeiro, b) fevereiro, c) março, d) abril, e) maio e f) junho.

\section{3 - RESULTADOS E DISCUSSÃO}

As análises aqui apresentadas foram feitas com dados da simulação do MRE sem nenhum tipo de correção do erro sistemático (Marengo et al., 2005). Esse critério foi

$$
R V a=1-\frac{\sum_{j=1}^{n}\left(V_{p, j}-V_{o, j}\right)}{\sum_{j=1}^{n}\left(C_{i}-V_{o, i}\right)}
$$

onde $\mathrm{V}_{0}$ é o valor da variável observada e $\mathrm{V}_{\mathrm{p}}$ é o valor da variável prevista e $\mathrm{C}_{\mathrm{i}}$ é o valor da MLT. Para esse parâmetro foi usada como valor comparativo a média climatológica (1971-2000) dos valores pentadais, quinzenais e mensais nos meses de janeiro a junho. $\mathrm{O}$ valor de RVa seria 1 para uma simulação perfeita (valores simulados iguais aos observados), maior que zero para simulações melhor que a climatologia e valores negativos para simulações piores que os valores climatológicos.


escolhido com o objetivo de analisar os dados brutos advindos da modelagem sem o uso de nenhum artifício estatístico de correção. Análises estão sendo feitas para se investigar se há alguma melhora nos resultados quando os dados são corrigidos com o uso de densidade de distribuição de probabilidades (PDFs). 


\section{1 - Variabilidade diária, pentadal e quinzenal}

A figura 2 mostra uma comparação da variabilidade diária da precipitação observada e a simulada pelo MRE na bacia hidrográfica do Açude Castanhão. Nota-se por essas figuras que a precipitação simulada é subestimada na escala diária nos meses de fevereiro, março, abril e maio e superestimada nos meses de janeiro e junho. Março (figura 2d) é o mês que ocorreram as maiores superestimativas do observado comparado ao simulado pelo MRE.

Simulações de precipitação por modelagem dinâmica dependem das características de cada modelo numérico (parametrizações físicas) e principalmente para regiões tropicais como estes resolvem à escala de nuvens convectivas e suas interações com a atmosfera (Arakawa, 2004). Marengo et al. (2005), mostrou que para a bacia do Rio São Francisco, o MCGA do Centro de Previsão de Tempo e Estudos Climáticos do Instituto Nacional de Pesquisas Espaciais (CPTEC/INPE) apresentou simulações diárias sempre acima do observada, no período de 1951-2001. Previsões de precipitação para a bacia do Rio São Francisco foram feitas por Marengo et al. (2005) para o período de 1998-2001. Seus resultados mostraram que o MCGA do CPTEC/INPE superestimou sistematicamente a chuva em toda a bacia, enquanto as previsões dos modelos regionais ETA e BRAMS (Brasilian Regional Atmospheric Model System) não apresentaram erros sistemáticos, embora suas previsões tenham sido muito semelhantes às geradas pelo modelo global com correção pela curva de distribuição de probabilidade acumulada diária. Histogramas diários (1971-2000) para os meses de janeiro a junho, para cada um dos 10 membros do MRE (agrupados em um único gráfico) e sua média e o observado no
Açude Castanhão são mostrados na figura 3. Na dispersão dos membros as freqüências acima de $60 \%$ são para intensidades inferiores a $10 \mathrm{~mm} / \mathrm{dia}$. Todos os membros apresentam dispersão muito similar em todos os meses, com uma maior variabilidade entre suas intensidade de $10 \mathrm{~mm} / \mathrm{dia}$ a $30 \mathrm{~mm} / \mathrm{dia}$.

O histograma de freqüência médio mostra que o MRE apresentou um predomínio de maiores (menores) freqüências entre as intensidades de $5 \mathrm{~mm} / \mathrm{dia}$ e $20 \mathrm{~mm} /$ dia (abaixo de 5 $\mathrm{mm} / \mathrm{dia}$ ). Para intensidade acima de $20 \mathrm{~mm} / \mathrm{dia}$, houve melhor desempenho das simulações do MRE em todos os meses comparado aos dados observados. Seth et al. (2004) fizeram uma comparação entre a chuva diária obtida de um MR (Pen State/National Center for Atmospheric Research (NCAR) Mesoescale Model (MM5) - Giorgi \& Bates 1989; Giorgi, 1990) com dados observados em estações meteorológicas para uma área do Nordeste do Brasil (seu setor norte). Este MR foi inicializado pelos dados de re-análises do National Center for Atmospheric Prediction (NECP/NCAR), para os meses de janeiro a maio de 1983 e 1985 . Nos seus resultados o MRE simulou melhores eventos de chuva menor $5 \mathrm{~mm} /$ dia e teve pior desempenho em eventos acima de $15 \mathrm{~mm} / \mathrm{dia}$.

Para os meses de fevereiro a maio, os resultados dos histogramas foram similares aos de Galvão et al. (2005), em estudos realizados para a bacia dos rios Pirapama (600 $\mathrm{Km}^{2}$ ) e bacio do Rio Piancó $\left(4550 \mathrm{Km}^{2}\right)$ nos reservatórios de Pirapama e Coremas localizados no setor norte do NEB. Nesses seus resultados, em ambos os reservatórios (ver suas figuras $3 \mathrm{a}$ e $3 \mathrm{~b}$ ) foram encontrados superestimativas do MRE na freqüência de chuvas mais fracas, subestimativa nas intensidades de precipitação intermediária e freqüências próximas as observadas para precipitações mais intensas.


Figura 3 - Histogramas de precipitação diária dos dez membros do MRE (gráficos da esquerda) e sua média e o observado (gráficos da direita). a) e b) janeiro, c) e d) fevereiro, e) e f) março, g) e h) abril, i) e j) maio e k) e l) junho. Nos gráficos da direita linha sólido (observado) e tracejado (MRE). 



Figura 3 - Continuação 


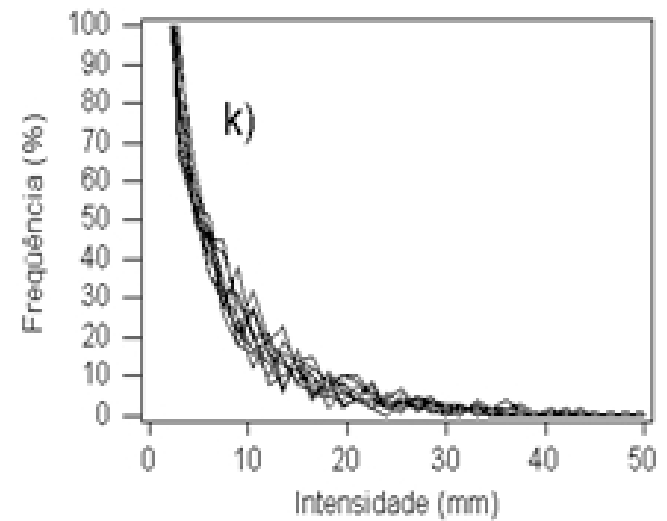

Figura 3 - Continuação

A variabilidade interanual pentadal (figuras não mostradas) mostraram as seguintes características entre a precipitação observada e a simulada na bacia do Açude Castanhão. Para a primeira pêntada em quase todos os meses o MRE produziu chuvas menores do que as observadas, exceto nos meses de janeiro e junho. Nesses meses os totais pentadais do MRE foram superiores a precipitação observada. Na segunda pêntada, em janeiro o MRE o superestimou o total observado em grande parte dos anos.

Em fevereiro não predominou nenhuma tendência para valores superiores ou inferiores, quando comparado os totais entre o MRE e o observado. Totais pentadais aproximados foram mais verificados a partir da década dos anos 80. Em março, na segunda pêntada, ocorreu uma predominância dos valores observados serem sempre maiores do que os simulados pelo MRE. Característica persistente em abril, com diferenças em intensidade mais significativas após os anos 80 .

Para maio, ocorreu uma superestimativa dos totais do MRE em relação ao observado de 1971 até aproximadamente 1983, após esses anos os valores observados superaram os simulados. Esse total foi maior do que o simulado pelo MRE, mas intensamente, principalmente nos anos de La Niña (1974, 1984, 1986 - Philander, 1990), e em 1982. Totais simulados mais próximos dos observados podem ser vistos nos anos de El Niño (1983, 1987 e 1998 - maior evento de El Niño já observado). Para junho, o MRE apresentou totais pentadais maiores dos que os de precipitação observada, porém, com diferenças não intensas em magnitude.

$\mathrm{Na}$ terceira pêntada as seguintes características mensais interanuais puderam ser identificadas. Em janeiro, os totais pentadais ao longo dos anos 1971-2000 são em geral abaixo de $40 \mathrm{~mm}$ tanto observado como estimado pelo MRE, pesar do MRE apresentar valores acima do observado na maioria dos anos. Em fevereiro, foi observada uma maior proximidade entre os totais do MRE e a precipitação média na bacia do Açude

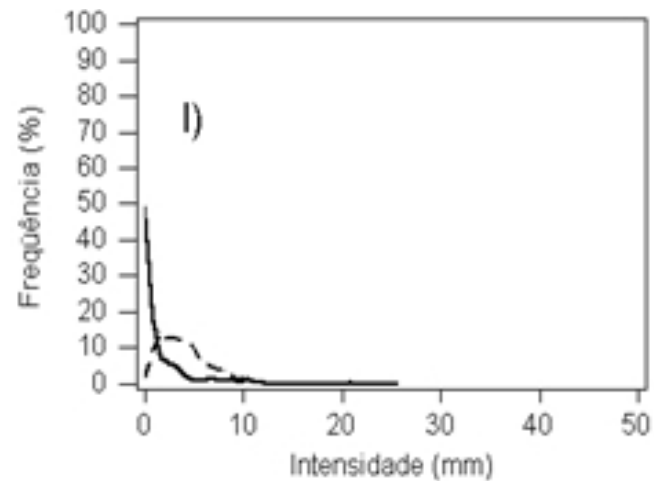

Castanhão. Fez-se exceção os anos de 1985, 1991, 1994, 1996 e 1998, cujos totais do MRE foram superiores a precipitação observada com diferenças mais marcantes em intensidade.

Quanto ao mês de março, predominou uma superestimativa da precipitação observada relacionada à advinda do MRE, porém sem grandes diferenças na intensidade, a despeito dos anos de 1994, 1998, 1994 e 2000 em que essas diferenças foram mais acentuadas. Em abril, ao longo de todos os anos (19712000), manteve-se a característica de março, com diferenças significativas entre a precipitação observada e a simulada pelo MRE. Em alguns anos foi observado o dobro ou mais da intensidade, principalmente entre os anos de 1980 e 2000. Em maio também essa característica entre a precipitação observada e simulada foi marcante, entretanto sem diferenças expressivas. Porém, nos anos de 1994, 1998, 1994 e 2000 as mesmas foram maiores em magnitude. Para junho as características foram similares às mencionadas para o mês de janeiro.

Nas quartas e quintas pêntadas para os meses de janeiro e junho as características foram semelhantes. O MRE manteve o erro sistemático com precipitação simulada maior do que a observada na bacia do Açude Castanhão, e tanto no observado como no MRE as precipitações foram inferiores a $40 \mathrm{~mm}$. Em fevereiro, as simulações apresentaram totais mais próximos dos valores observados em ambas as pêntadas, porém na variabilidade interanual (1971-2000) predominou uma subestimativa (superestimativa) na quarta pêntada (na quinta pêntada nos anos de 1992 e 1995 mais significativas em intensidade). Em março, o bias é seco (úmido) do MRE, indicativo de totais simulados inferiores (superiores) as observações na quarta (quinta) pêntadas. Na quarta (quinta) pêntada o bias seco (úmido) foi mais predominante entre 19711982 (1971-1986 mais significativamente).

Para sexta pêntada, em janeiro os valores simulados foram mais próximos das observações. Em fevereiro, na maioria dos anos o MRE subestimou a precipitação 
observada, característica mais clarividente no período de 1971-1986. Nos meses de março, abril, e maio mantiveramse uma superestimativa dos dados observados em relação aos simulados pelo MRE. Para março o intervalo de anos apresentando essa característica foi 1971-1986. Para abril foi 1983-1998 e maio de 1974-1979 e 1985-1995, principalmente. Em junho a sexta pêntada, a precipitação na bacia do Açude Castanhão, simulada pelo MRE quando comparada aos dados observados teve configuração similar a do mês de janeiro.

As análises dos dados pentadais, variabilidade interanual, mostraram que o MRE tem um viés seco nos meses de fevereiro a maio, e um úmido em janeiro e junho. Outra característica típica observada foi que entre aproximadamente 1971 até os anos 80, na maior parte das pêntadas nos meses de fevereiro a maio houve um maior déficit do simulado em relação ao observado. Esses anos, principalmente, a década de 1980 foi mais chuvosa, com eventos de La Niña, que estão associados a chuvas mais regulares no NEB (Ropelewski e Halpert, 1996). Na década de 90, climatologicamente mais seca ao longo do globo (Latif et al. 1997), as precipitações pentadais simuladas pelo MRE se aproximaram mais dos dados observados. Alguns estudos mostram que nessa última década ocorreu redução da precipitação ao longo do globo associada ao anômalo aquecimento no Pacífico Tropical (Goddard e Graham, 1997). Segundo Latif et al. 1997 a causa desse aquecimento ainda é fonte de estudo, embora algumas pesquisas apontem que o mesmo seja conseqüência do aquecimento global (Meehl e Washington, 1996).

A precipitação na bacia do Açude Castanhão na primeira quinzena dos meses de janeiro a junho observada e simulada pelo MRE é mostrada na figura 4.

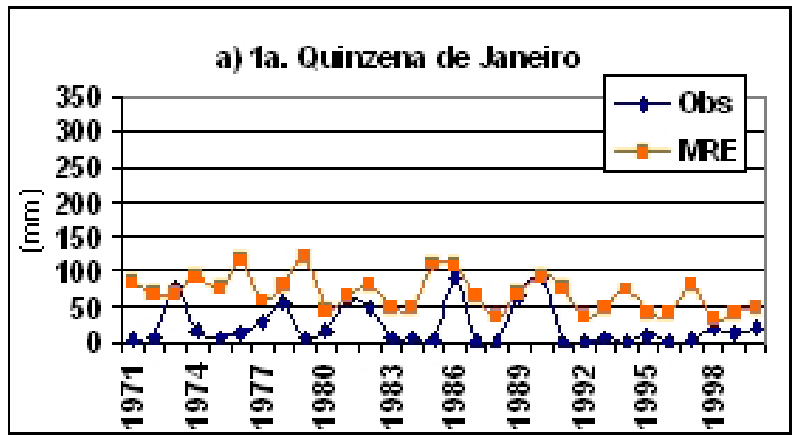

Para o mês de janeiro o MRE, como já comentado nas análises pentadais, simulou mais precipitação do que a observada, representando razoavelmente a variabilidade interanual com alguma defasagem até os anos 90, e não identificando após esses anos os picos máximos de precipitação observada (figura 4a). Pode-se observar neste mês de janeiro uma defasagem do MRE de uma pêntada em simular os máximos e mínimos da precipitação observada. Anos com a primeira quinzena bem simulada foram: 1973, 1982, 1986, 1989 e 1990. No mês de fevereiro, as precipitações da primeira quinzena observadas foram superiores as simuladas, com maior consistência entre o previsto e o estimado pelo MRE a partir do final da década de 80 (figura 4b). O MRE não conseguiu simular com melhor desempenho em intensidade a precipitação mais excessiva (escassa) de precipitação anos de 1974, 1979, 1986 (1983).

Durante o mês de março, nessa primeira quinzena do mês, também foi observado uma subestimativa do MRE em relação às observações, com o MRE apresentando pequena amplitude de variabilidade interanual. Diferenças mais marcante nas intensidades foram observadas nos anos de 1974 e 1980, nos demais anos os valores simulados e observados estiveram mais próximos em intensidade. Nos meses de abril e maio, embora tenha se mantido a característica dos totais quinzenais observados, sendo maiores que os simulados pelo MRE, ocorreu uma melhor identificação em fase (mesma direção das curvas simuladas e estimadas) e proximidade entre esses valores quinzenais (figuras $4 \mathrm{~d}$ e $4 \mathrm{e}$ ). Em junho, como verificado nos dados pentadais, a configuração entre os totais do MRE e a precipitação observada foi parecida com a do mês de janeiro (Figura 4f).

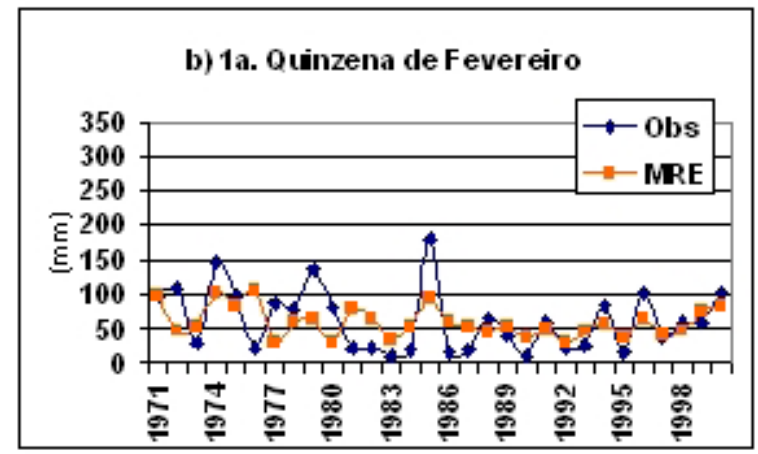

Figura 4 - Variabilidade interanual da precipitação ( $\mathrm{mm}$ ) observada (obs) e simulada pelo modelo regional espectral (MRE) na primeira quinzena. a) janeiro, b) fevereiro, c) março, d) abril, e) maio e f) junho. 

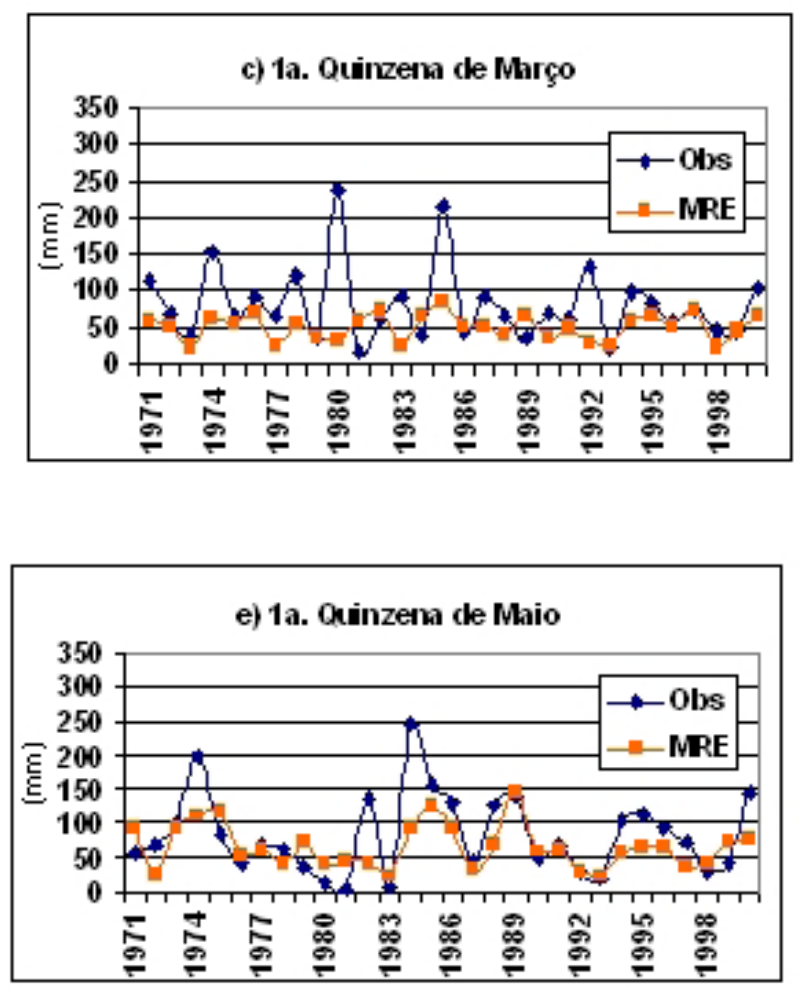

Figura 4 - Continuação

A figura 5 mostra a variabilidade interanual da segunda quinzena da precipitação na bacia do Açude Castanhão nos meses de janeiro a junho observada e simulada pelo MRE. Para janeiro ocorreu o inverso em relação a primeira quinzena. O observado predominou com totais superiores ao simulado pelo MRE, além disso, o MRE não foi sensível à variabilidade interanual, principalmente os picos de chuva mais significativos após os anos 80 (figura 5a). Em fevereiro, a configuração do MRE conseguiu reproduzir com bom desempenho a variabilidade interaranual, com uma maior diferença entre o simulado e o observado na segunda quinzena do ano de 1992 (figura 5b).



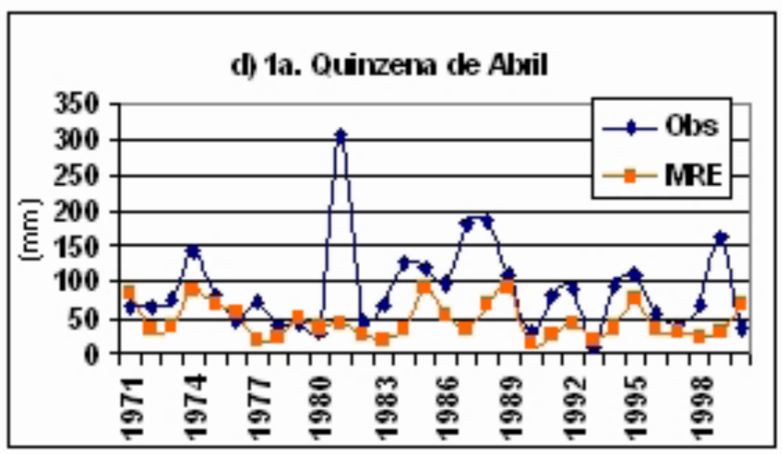

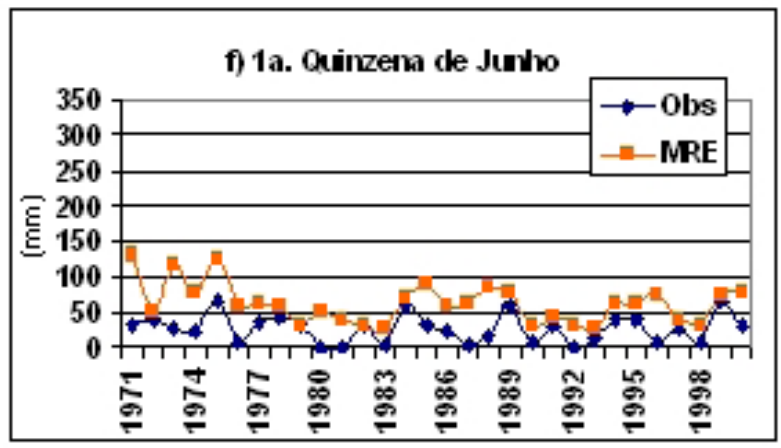

Em março e abril, configurações similares às verificadas na primeira quinzena desses meses entre o simulado pelo MRE e as observações podem ser visualizadas na figura $5 \mathrm{c}$. As simulações ao longo dos anos, em particular após os anos 80 , foram consistentes em fase (direções das curvas) com os valores observados com totais mais próximos entre ambos (figuras $5 \mathrm{c} \mathrm{e}$ 5d). Esta característica não esteve tão evidente em maio como na primeira quinzena, apesar dos dados simulados se aproximarem dos dados observados em particular nos últimos quinze anos de estudo (Figura 5e). Em junho o MRE manteve, nesta segunda quinzena, a mesma superestimativa de precipitação comparado aos dados observados (figura 5f).

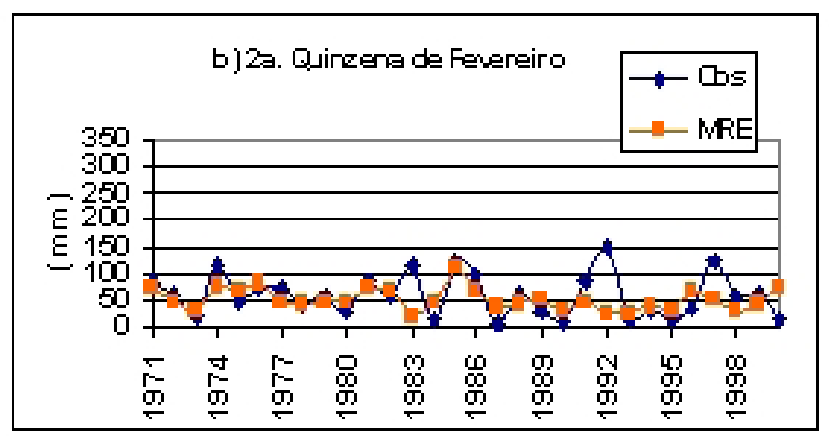

Figura 5 - Variabilidade interanual da precipitação $(\mathrm{mm})$ observada (obs) e simulada pelo modelo regional espectral (MRE) na primeira quinzena. a) janeiro, b) fevereiro, c) março, d) abril, e) maio e f) junho. 

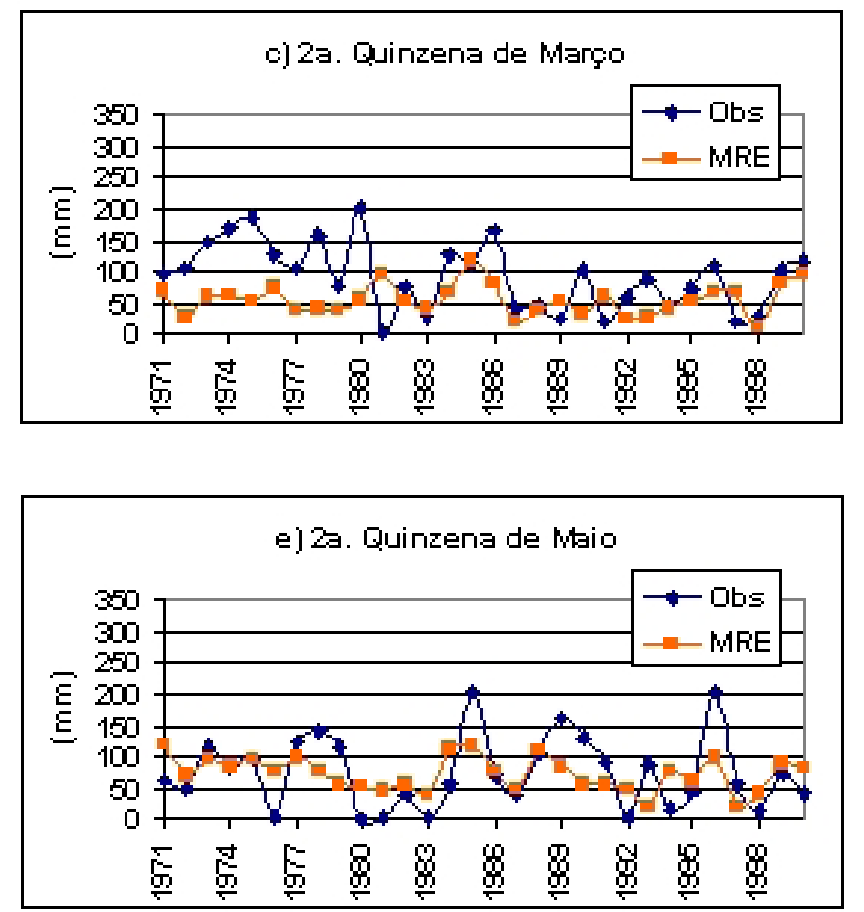

Figura 5 - Continuação

Uma das possíveis causas das simulações do MRE não representarem melhor o curso da distribuição interanual de precipitação abaixo da escala sazonal (três meses), com melhor desempenho podem ter algumas razões. A primeira seria uma não assimilação de condições dinâmicas de superfície sobre o NEB (mudanças bruscas, por exemplo, na vegetação típica da região - caatinga), que deve mudar o balanço de massa, momento, radiação e trocas entre a superfície atmosfera. Essas trocas interferem diretamente na distribuição de precipitação ao longo do NEB. Nessa rodada de 1971-2000 foi considerada uma vegetação homogênea em toda a área do NEB. Além disso, as características pedológicas do NEB também foram consideradas homogêneas. Esses questionamentos podem ter influência significativa na precipitação a ser simulada por modelos dinâmicos (Sun et al. 2005).

Para os meses de janeiro e junho duas questões podem ser endereçadas a fraca sensibilidade do MRE em simular a precipitação observada nessa bacia do Açude Castanhão localizada na região semi-árida do NEB. Uma é que como a primeira condição de contorno para a simulação do MRE é a TSM, na base mensal a mesma explica muito pouco das precipitações pré (novembro a janeiro) e pós-estação chuvosa (junho em diante) do setor norte do NEB (fevereiro a maio). Da ordem de menos de $15 \%$ da variabilidade da precipitação nesses meses (Alves et al. 1993). Além disso, os sistemas que causam chuvas nesses meses são mais transientes (Vórtices Ciclônicos de Ar Superior-VCAS em janeiro e Ondas de Leste em junho), atuando em geral abaixo da escala de um mês sendo estes de
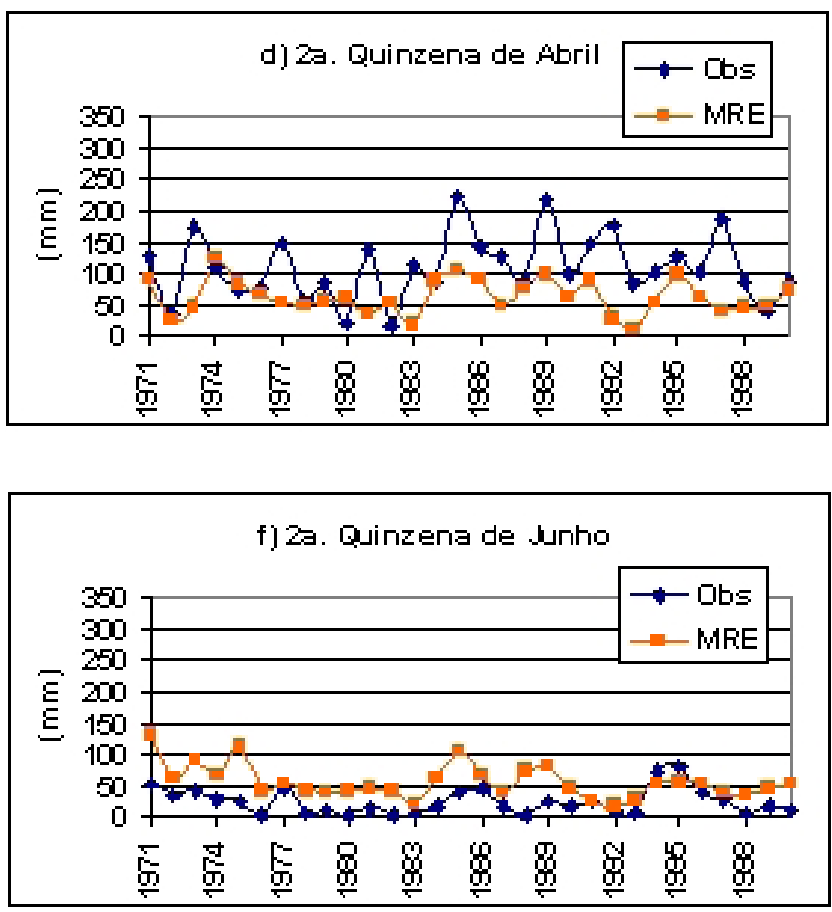

difícil previsão em modelos dinâmicos rodados para escala de tempo climatológica (simulação em geral para períodos acima de um mês).

Essa última questão parece ser crucial, visto que nessas rodadas climatológicas o modelo assimila apenas uma vez uma condição de "análises" (dados observados em superfície e na atmosfera mesclados com dados de satélites) para ser inicializado. Resultados mais recentes como os de Quian et al. (2003) e Seth et al. (2004) mostraram que a reinicialização pode melhorar o desempenho de MRs em simular quantitativamente a distribuição de precipitação. A resolução da TSM pode também ajudar na melhora futura de resultados de modelagem intrasazonal. Sun et al. (2005), sugere que valores inferiores a $1^{\circ}$ de latitude versus longitude, principalmente no Atlântico Tropical, poderiam ser usados para testar esses possíveis benefícios, além de os mesmos serem incorporados no modelo, por exemplo, em vez da escala mensal, na base semanal.

\subsection{Variabilidade pentadal, quinzenal e mensal para os anos de contrastes climáticos}

As figuras 6,7 e 8 mostram a variabilidade da precipitação pentadal, quinzenal e mensal para os meses de janeiro a junho (suas médias, climatologia (1971-2000), desvio padrão e suas anomalias) para os anos classificados como Normais, de La Niña e de El Niño no Pacífico Tropical.

Nota-se que para todos os meses, em todas as composições de anos, a simulação do MRE capturou a tendência das 
variabilidades principalmente pentadal da precipitação observada, embora que mantendo o erro sistemático de subestimativa. Uma característica mostrada nessas análises é a pouca dispersão das simulações do MRE que apresenta pequena variabilidade nos valores de desvio padrão com relação aos valores observado nas escalas pentadal, quinzenal e mensal.

Relacionado às anomalias nesses anos de contrastes climáticos, o MRE conseguiu reproduzir o sinal das anomalias. Em anos de La Niña (El Niño e Normais) em quase todos os
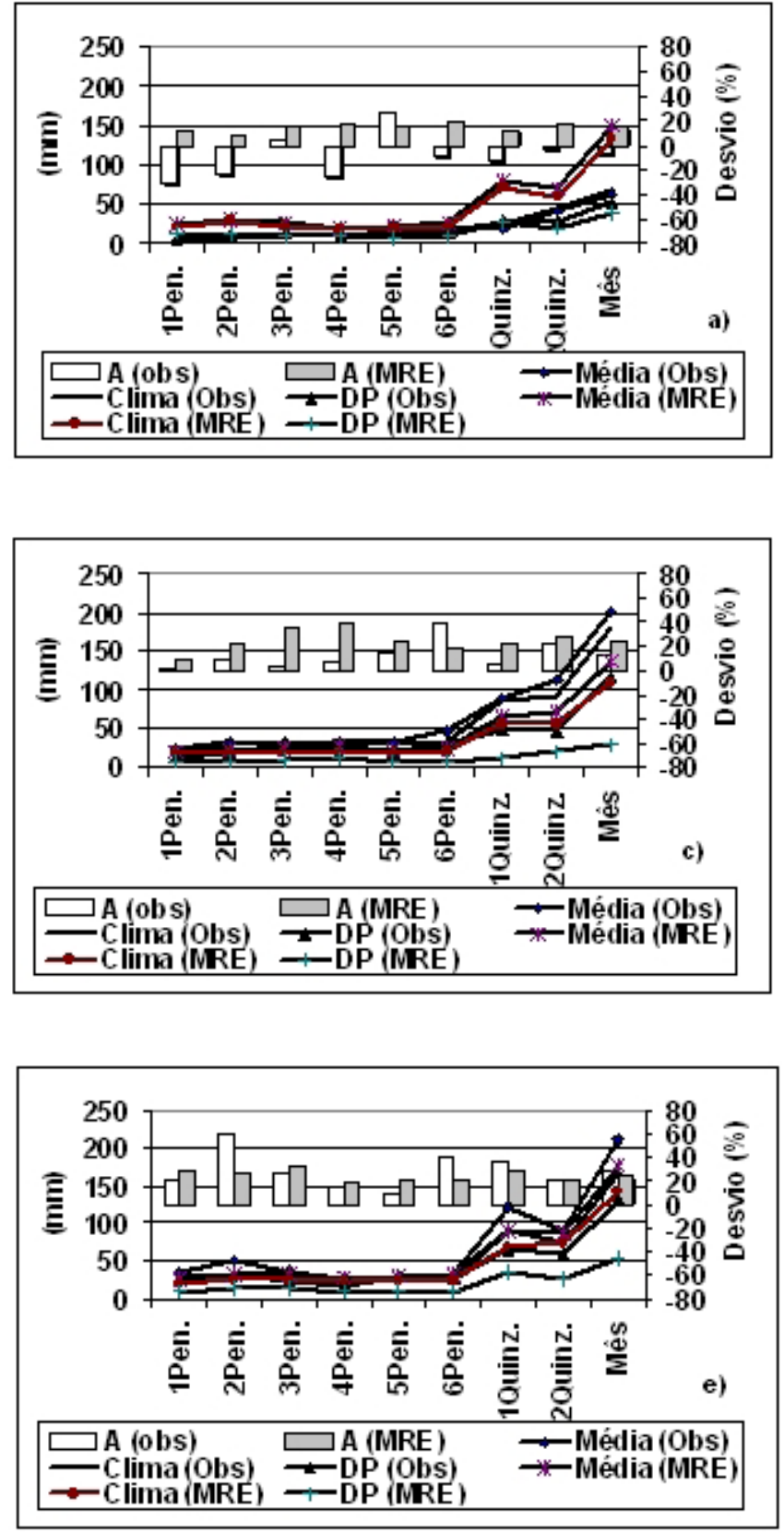

meses de janeiro a junho o MRE mostrou um mesmo sinal de anomalias do observado com predomínio de anomalias positivas (negativas) de precipitação. Esses resultados indicam que o MRE reproduz, mesmo em escala de uma média bacia hidrográfica do semi-árido do Nordeste do Brasil, a variabilidade interanual de grande escala da precipitação tropical cuja representação é mais típica em MCGAs. Sun et al. (2005) mostrou evidências dessa reprodução na precipitação sobre o Nordeste do Brasil e Atlântico tropical em análises do MRE/97.
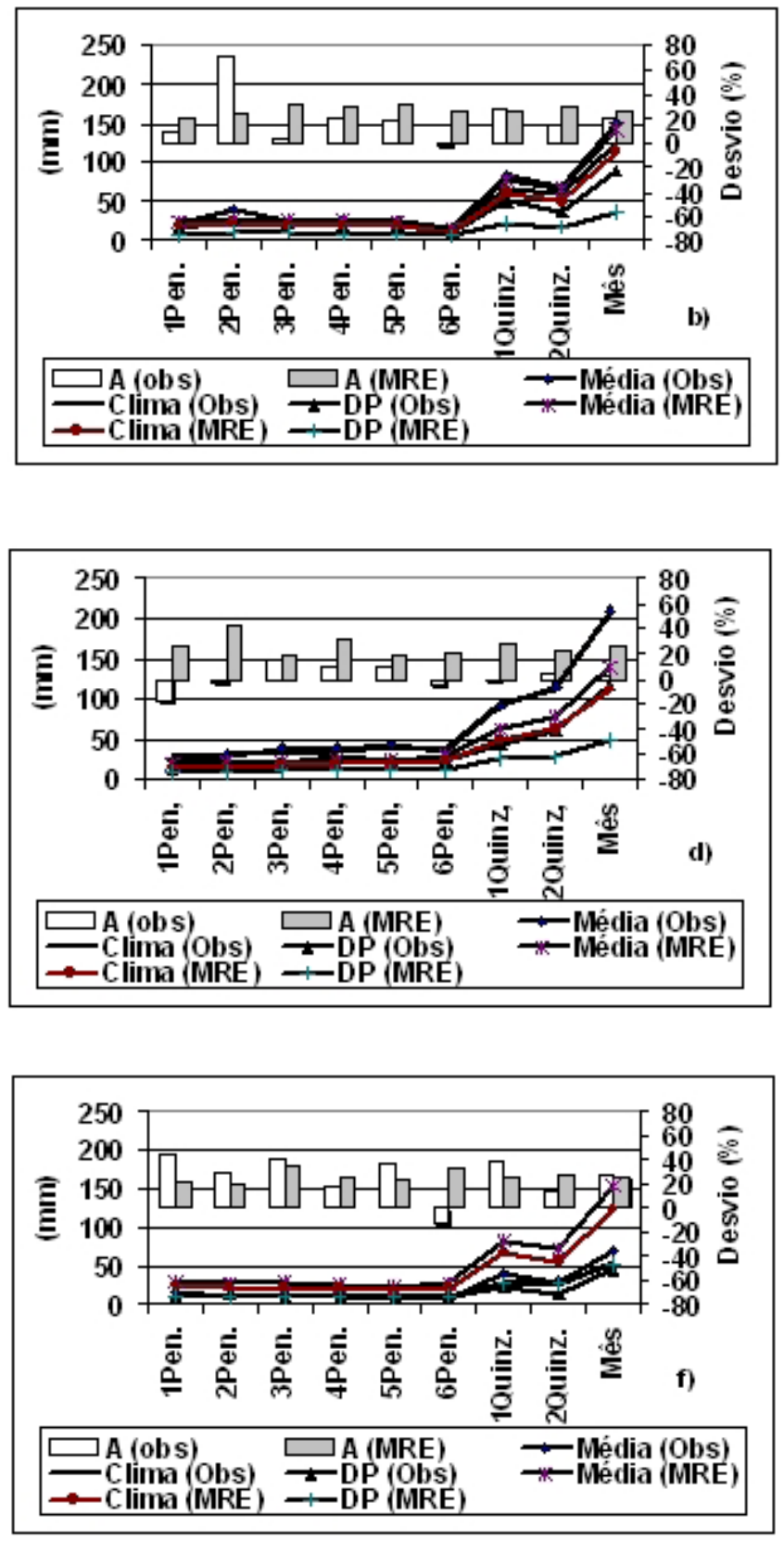

Figura 6 - Variabilidade pentadal, quinzenal e mensal ( $\mathrm{mm}$ ) para os anos de La Niña e suas anomalias normalizadas pela média (\%) eixo da direita para os dados observados e simulados pelo MRE. A na legenda significa anomalia, clima refere-se à média observada no período de 1971-2000, média refere-se o valor para a composição de anos de La Niña e DP o desvio padrão. As barras com sombras indicam significância estatística de $95 \%$. 

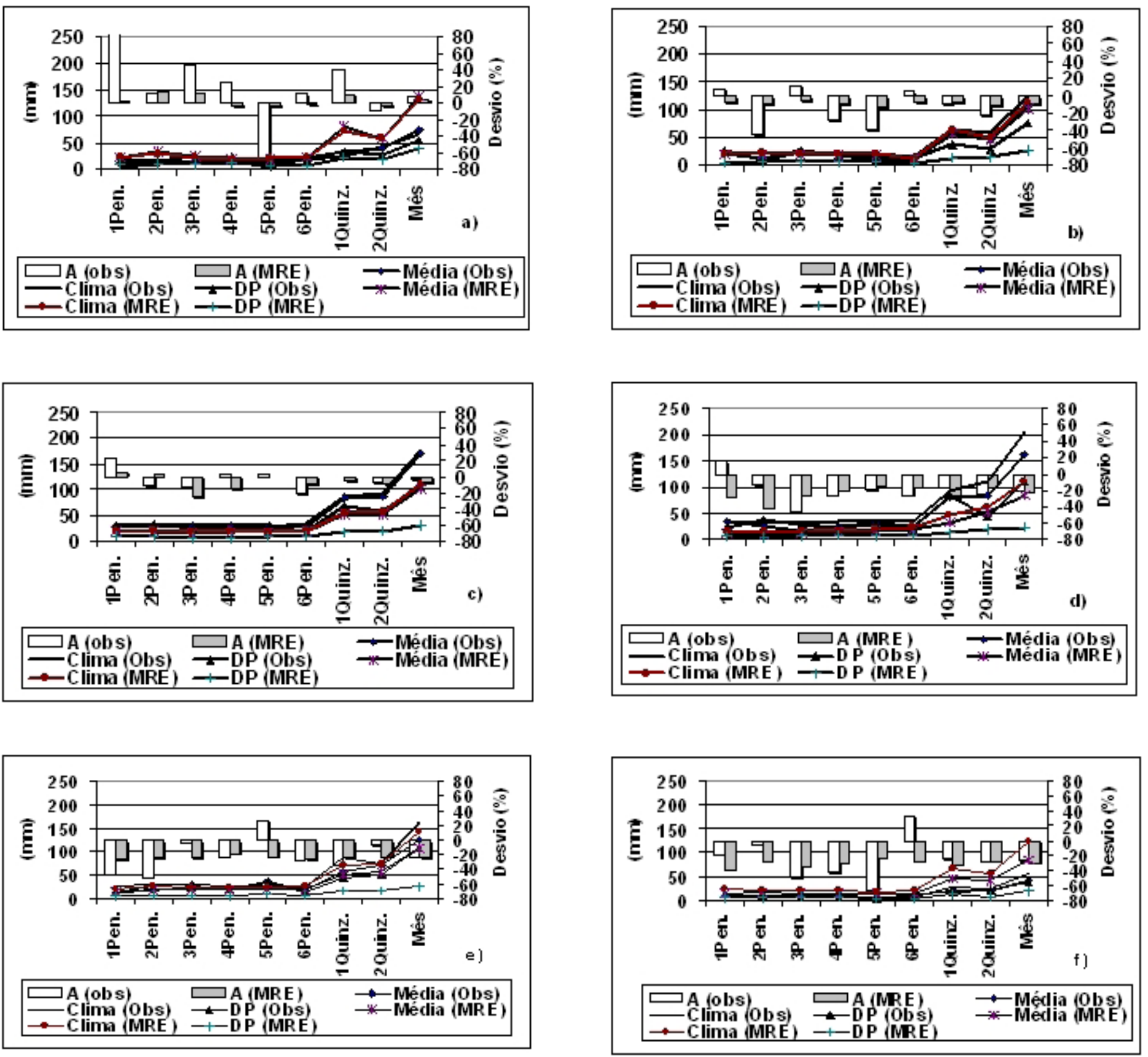

Figura 7 - Variabilidade pentadal, quinzenal e mensal $(\mathrm{mm})$ para os anos Normais e suas anomalias normalizadas pela média (\%) eixo da direita para os dados observados e simulados pelo MRE. A na legenda significa anomalia, clima refere-se à média observada no período de 1971-2000, média refere-se o valor para a composição de anos Nornais e DP o desvio padrão. As barras com sombras indicam significância estatística de $95 \%$.

A tabela 1 mostra a comparação entre o termo de redução da variância da simulação do MRE e os valores observados para os meses de janeiro a junho. Nota-se por essa tabela que para os meses de janeiro e junho não ocorreu ganho de redução da variância nos valores pentadais de ambos os meses, os valores dessa variável são negativos. Isto é, o uso da climatologia (MLT) como prognóstico nesses meses teve melhor desempenho do que as simulações do MRE.

Para os meses de fevereiro a maio os resultados mostram que houve uma considerável redução da variância com valores da ordem de $10 \%$ a $45 \%$, indicando um ganho considerável das simulações pentadais do MRE relacionado à simulação mais comum usada em termos comparativos que é a climatologia - MLT (Tucci et al., 2005). Esses valores da ordem de 10\% a $45 \%$ da redução da variância são semelhantes aos encontrados no estudo de Tucci, et al. (2005) para previsões de um a seis meses de antecedência nas vazões trimestrais para a bacia do Rio São Francisco. 

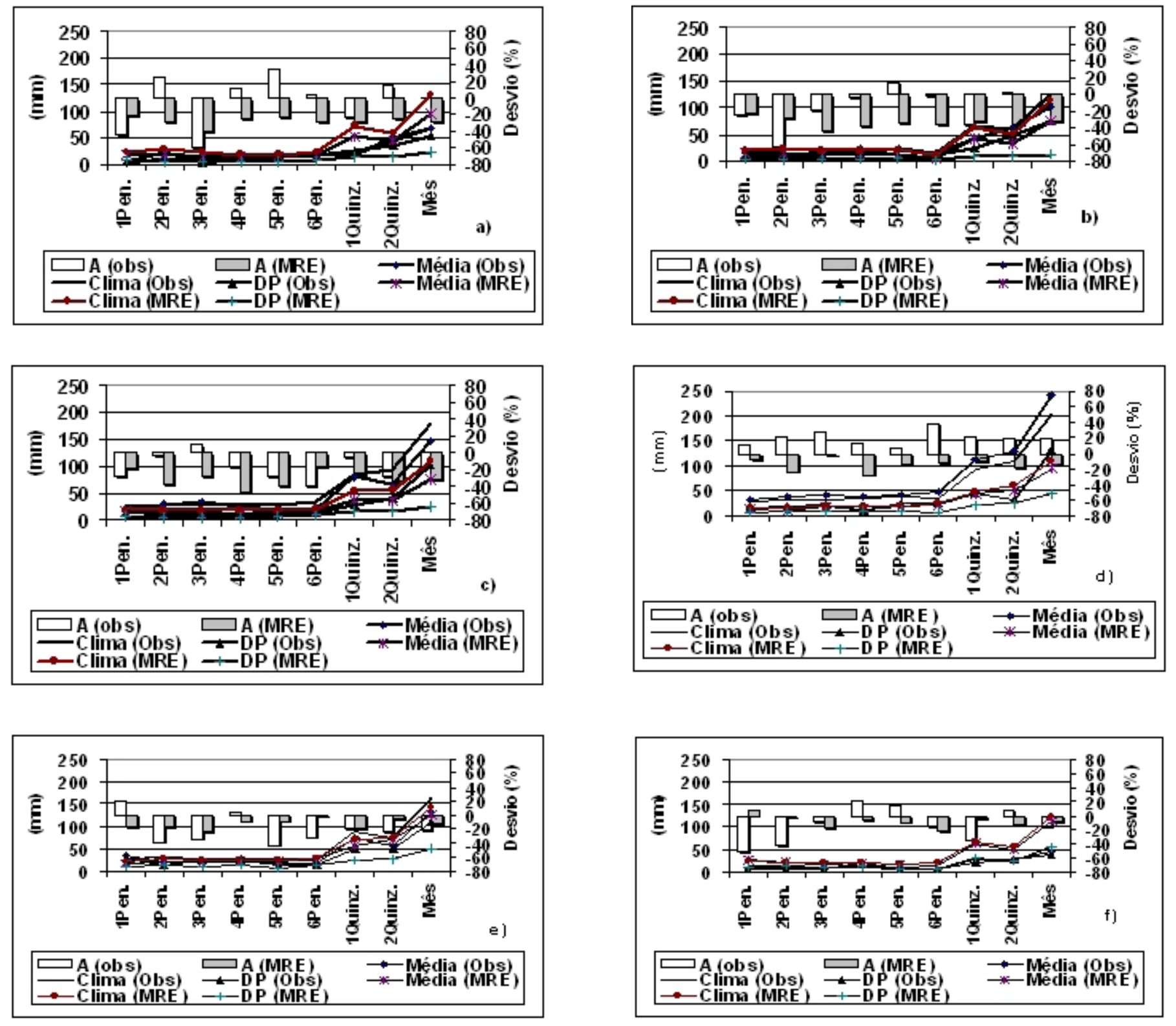

Figura 8 - Variabilidade pentadal, quinzenal e mensal $(\mathrm{mm})$ para os anos de El Niño e suas anomalias normalizadas pela média (\%) eixo da direita para os dados observados e simulados pelo MRE. A na legenda significa anomalia, clima refere-se à média observada no período de 1971-2000, média refere-se o valor para a composição de anos de El Niño e DP o desvio padrão. As barras com sombras indicam significância estatística de $95 \%$.

Tabela 1 - Variabilidade pentadal mensal (1971-2000) do parâmetro de redução da variância (\%) da simulação da MRE.

\begin{tabular}{lccclll}
\hline & Jan & Fev & Mar & Abr & Mai & Jun \\
1Pêntada & $-15,74$ & $-0,09$ & 0,29 & 0,35 & 0,39 & $-1,39$ \\
2Pêntada & $-7,72$ & 0,2 & 0,17 & 0,14 & 0,22 & $-3,1$ \\
3Pêntada & $-4,04$ & 0,14 & 0,15 & 0,22 & 0,3 & $-2,26$ \\
4Pêntada & $-0,7$ & 0,2 & 0,28 & 0,25 & 0,34 & $-2,01$ \\
5Pêntada & $-1,22$ & 0,14 & 0,2 & 0,3 & 0,26 & $-2,26$ \\
6Pêntada & $-1,94$ & 0,21 & 0,21 & 0,45 & 0,25 & $-5,39$ \\
& & & & & & \\
\hline
\end{tabular}




\section{CONCLUSÕES E RECOMENDAÇÕES}

Entre as principais conclusões do estudo citam-se: o MRE tem um erro sistemático com predomínio de subestimativa (suprestimativa) da precipitação pluviométrica na bacia do Açude Castanhão-Ce nas escalas de tempo pentadal, quinzenal e mensal nos meses de fevereiro a maio (janeiro e junho). Quantitativamente nessas escalas o MRE apresentou valores mais próximos do observado a partir da segunda metade da década de 80 , período que foi climatologicamente mais seco sobre o NEB, em particular os anos 90. Relacionado aos desvios o MRE foi capaz de capturar o sinal das anomalias positivas (negativas) de precipitação na bacia do Açude Castanhão intrasazonalmente e mensalmente que predominaram nos anos de contrastes climáticos de La Niña (El Niño e Normais) observados no Pacífico Tropical. Histogramas de freqüências em várias intensidades de precipitação diária mostraram que a simulação do MRE superestimou chuvas consideradas fracas (em geral inferiores a $10 \mathrm{~mm}$ ), subestimou chuvas moderadas (acima de 10 inferiores a $30 \mathrm{~mm}$ ), e teve melhor desempenho para as freqüências de chuvas fortes (acima de $30 \mathrm{~mm} /$ dia).

Para estudos futuros, principalmente relativos a melhorar o desempenho quantitativo do MRE na variabilidade interanual nas escalas diária, pentadal e quinzenal, sugerem-se rodadas de simulação com assimilação de dados ao longo da mesma (dados de re-análises ou médias climatológicas diárias, pentadais, por exemplo, de vento, temperatura, umidade específica, etc.). Além de testar também o MRE aninhado a outros MCGAs. Comparar também os resultados do MRE corrigidos (através das curvas de freqüências amostrais acumuladas ou com preservação dos dois primeiros momentos estatísticos), com os dados originais da simulação para identificar o ganho quantitativo obtido.

\section{5 - AGRADECIMENTOS:}

Aos revisores anônimos da RBMET cujas críticas e sugestões foram importantes para o aprimoramento científico e apresentação do artigo.

\section{REFERÊNCIAS BIBLIOGRÁFICAS}

ALVES, J. M. B.; CAMPOS, J. N. B.; FILHO, F. A. S.; MONCUNNIL, D. F.; DA SILVA, E. M.; BARBOSA, W. L.; FERREEIRA, A. G.; SUN, L.; MOURA, A. D. Uma avaliação preliminar de simulações climáticas de um modelo regional espectral aninhado em um modelo global (ECHAM4.5) sobre o setor norte da região Nordeste do Brasil (1971-2000). Revista Brasileira de Meteorologia, v.20, n.2, p.191-206. 2005.
ARAKAWA, A. The cumulus parameterization problem: past, present and future. Journal of Climate, v.17, n.13, p. 24932525. 2004.

COLLISCHONN, W. Simulação hidrológica de grandes bacias. Porto Alegre: UFRGS. Tese. Instituto de Pesquisas Hidráulicas da Universidade Federal do Rio Grande do Sul. 194p. 2001.

DA SILVA, A M.; YOUNG, A C. e LEVITUS, S. Algorithms and Procedures, vol.1, Atlas of Surface Marine Data. Maryland, National Oceanic and Atmospheric Administration, 83 pp. 1994.

GALVÂO, C. O. Aplicabilidade em Recursos Hídricos da previsão de precipitação de longo prazo no Nordeste do Brasil. Tese, Instituto de Pesquisas Hidráulicas da Universidade Federal do Rio Grande do Sul. Porto Alegre, Brasil. 1999.

GIORGI, F.; BATES, G. T. On climatological skill of a regional model over complex terrain. Monthly Weather Review. v.117, n.11, p.2325-2347. 1989.

GIORGI, F. On simulation of regional climate using a limited area model nested in a general circulation model. J. Climate, v.3, n.9, p.941-963. 1990.

GODDARD, L.; GRAHAM, N. E. El Niño in the 1990s. Journal of Geophysical Research, 102(C5), 10423-10436, 10.1029/97JC00463, 1997.

GRAHAM, N. E. Simulation of recent global trends . Science, v. 267, n.5198, p.666-671. 1995.

HARRISON, D. E.; LARKIN, N. K. El Niño-Southern Oscillation sea surface temperature and wind anomalies, 1946-1993. Review of Geophysics, v. 36, n.3, p. 353-399. 1998.

JUANG, H. M. H.; KANAMITSU, M. The NMC nested regional spectral model. Monthly Weather Review, v.122, n.1, p.3-26. 1994.

KILLADIS, G. N.; DIAZ, H. F. Global climatic anomalies associated with extremes in the Southearn Oscillation. Journal of Climate, v.2, n.10, p.1069-1090. 1989.

LATIFI. M.; KLEEMAN, R.; ECKERT, C. Greengouse warming, decadal variabilitiy, or El Niño? An attempt to understand the anomalous 1990s. Journal of Climate, v.10, n.9, p.221-2239. 1997.

MCGUFFIE, K.; HENDERSON-SELLERS, D. P. Forty years of numerical climate modelling. International Journal of Climatology. v.21, n.9, p. 1067-1109. 2001.

MARENGO, J. A. Observed and modeled historical hydroclimatic variabilility in South America: cases of the Amazon, São Francisco and Paraná-La Plata rivers. In: Regional hydrological Impacts of Climatic Change-Hydro climatic Variability. Proceedings of Symposium S6 held during Seventh IAHS Scientific Assembly at Foz do Iguaçu. 
Brazil. April 2005. IAHS -publ. 296, p.7-20. 2005.

MARENGO, J. A.; SAMPAIO, G.; CHOU, S. C.; SILVA DIAS, P. L. et al. Previsão de vazões de longo prazo na bacia do Rio São Francisco I: Previsão da precipitação. Revista Brasileira de Recursos Hídricos. Submetido, 12p. 2005.

MEEHL, G.; WASHINGTON, W. M. Pacific region climate change. Nature, v.382, n. 6586, p.56-60. 1996.

MOURA, A.D.; SHUKLA, J. On the dynamics of droughts in northeast Brazil: Observations, theory and numerical experiments with a general circulation model. Journal of Atmospheric Science, v.38, n.7, p.2653-2675. 1981.

NOBRE, P. On the genesis of anomalous SST and rainfall patterns over the tropical Atlantic Basin. (Ph.D. Thesis) - University of Maryland at College Park, Maryland, 1993. $151 \mathrm{p}$.

NOBRE, P.; SHUKLA, J. Variations of sea surface temperature, wind stress and rainfall over the tropical Atlantic and South America. Journal of Climate, v.10, n.4, p.2464-2479. 1996.

QUIAN, J. -H; SETH, A.; ZEBIAK, S. Renitialized versus continuous simulations for regional climate downscaling local climate. Monthly Weather Review., v.131, v.11, p.2857-2874. 2003.

PAN, H. L.; MARTH, L. Interaction beteween soil hydrology and boundary-layer development. Boundary Layer Meteorology, v.38, n.3, p.185-202. 1987.

PHILANDER, S. G. El Niño, La Niña, and Southern Oscillation. Academic Press, Londres, 289pp. 1990.

SERVAIN, J. Simple climatic indices for the tropical Atlantic Ocean and some applications, Journal of Geophysical
Research., 96(C8), 15137-15146, 10.1029/91JC01046, 1991.

SETH, A.; ROJAS, M.; LIEBMAN, B.; QUIAN, J. - -H. Daily rainfall analysis for South America from a regional climate model and station observations. Geophysical Research Letters. vol. 31, L077213.doi:10.1029/2003GL019220, 2004.

SOUZA, E.B. Um estudo observacional sobre o Padrão de Dipolo de anomalias de TSM no Oceano Atlântico Tropical. Dissertação de Mestrado em Meteorologia. INPE, São José dos Campos -SP, 1997. 138p. (INPE-6392-TDI/608).

SUN, L.; MONCUNILL, D.; HUILAN, L.; MOURA, A. D.; FILHO, F. A. S. Climate downscaling over Nordeste, Brazil, using the NCEP RSM97. Journal of Climate, v18, n.4, p..551-567. 2005.

SUN, L.; MONCUNILL, D.; HUILAN, L.; MOURA, A. D.; FILHO, F. A. S.; ZEBIAK, E. An operational dynamical downscaling prediction system for Nordeste Brazil and the 2002-04 real time forecast evaluation. Journal of Climate, v19, n.10., p.1990-2007. 2006.

ROPELEWSKI, C. F.; HALPERT, M. S. Quantifying Southern Oscillation-precipitation relationship. Journal of Climate, v.9, n.5, p.1043-1059. 1996.

TRENBERTH, K. E. The definition of El Niño. Bulletin of American Meteorological of Society. v.78, n.12, p.27712777. 1997.

TUCCI, C. E. M.; CLARK, R. T.; COLLISCHONN, W.; DIAS, P. L. S.; SAMPAIO, G. O. Long term flow forecast based on climate and hydrological modeling: Uruguay river basin. Water Resources Research, v.39, n.7, p.3 (1-11). 2003.

TUCCI, C. E. M.; SILVA, B. C. DA; COLLISCHONN, W. et al. Previsão de vazão de longo prazo na bacia do Rio São Francisco III: Previsão de vazão. Revista Brasileira de Recursos Hídricos. 13p. Submetido 2005. 